\title{
Resonant phenomena in colloidal crystals
}

\author{
T. Palberg, M. Würth, P. König, E. Simnacher, and P. Leiderer \\ Universität Konstanz, Fakultät für Physik, Konstanz, FRG
}

\begin{abstract}
Colloidal crystals of completely deionized suspensions of latex speres are subjected to oscillatory and steady shear, as well as to homogeneous and inhomogeneous electric fields. Various resonant phenomena observed in such experiments are reported.
\end{abstract}

Key words: Colloidal crystals; shear resonances; elasticity; shear flow; electric fields

Colloidal crystals are prepared from highly charged monodisperse suspensions of polystyrene latex spheres in a continuous deionization circuit. Details of both materials used [1] and of the deionization setup [2] are given elsewhere. Resonant torsional and shear vibrations of crystals are detected by monitoring the amplitude of periodic shifts in the angle of Bragg scattered light as a function of frequency [3] (Lock-in technique or FFT-frequency analysis). From the resonance frequencies measured in a cylindrical geometry by periodic excitation the shear modulus $G$ of the suspension is calculated [4]. Assuming a screened Coulomb potential for the interaction of particles a renormalized charge number [5] is derived and is found to increase with increasing particle concentration $c_{p}$.

Placed in a rectangular flow-through cell acting as resonator (depth: height $=1: 10$ ) with open ends, a crystalline suspension of $c_{p}=2.5 \cdot 10^{18} \mathrm{~m}^{-3}$ shows a single resonance of frequency $v_{\text {res }}=14 \mathrm{~Hz}$. The shear modulus derived via $G=4 \pi v_{\text {res }}^{2} /\left(1 / k_{x}^{2}+1 / k_{4}^{2}\right)$ agrees well with the values from the cylindrical geometry.

Under very slow $d c$-flow $\left(v_{p} \leqslant 7 \mu \mathrm{m} \mathrm{s}^{-1}\right)$ the crystalline solid moves with a plug-like velocity profile, and it is excited to resonances of $v_{\text {res }}=7 \mathrm{~Hz}$ by alternating stick-slip at the walls of stick-slip frequency $v_{s s}=3.5 \mathrm{~Hz}$. At slightly faster flow $\left(v_{p}=\right.$ 7-12 $\mu \mathrm{m} \mathrm{s}^{-1}$ ) there is depinning at all walls and the crystal moves without vibrational excitation, whereas increasing the flow further, results in, first, grinding of the solid into fine crystallites, and then, shear melting and a parabolic velocity profile $[1,6]$.

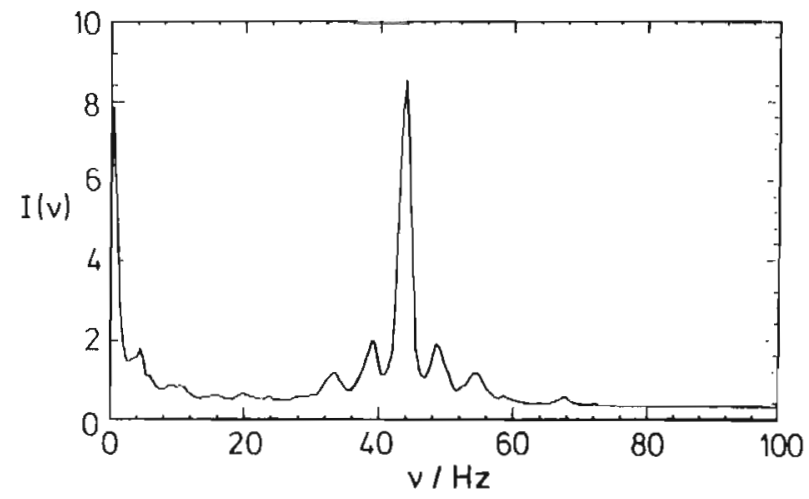

a

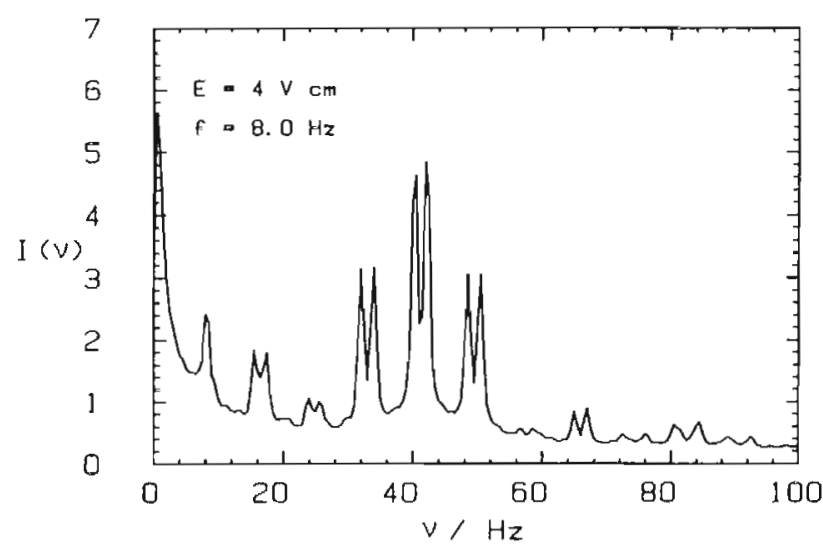

b

Fig. 1. Typical Doppler shift spectra (reference beam geometry) for a crystal in a weak homogeneous electric field of field strength $E=4 \mathrm{~V} \mathrm{~cm}^{-1} ; \mathrm{a}$ : $d c$ field, $b$ : $a c$ field with $v_{a c}=8 \mathrm{~Hz}$ 
When subjected to a weak homogeneous $d c$ electric field the crystal also flows through the cell in a pluglike manner. Doppler shift spectroscopy [7] in the reference beam geometry shows a splitting of the velocity peak, as depicted in Fig. 1a. In an ac field two splittings may be observed, as shown in Fig. 1b: one being that of the frequency of the applied field $v_{a c}$ [8], and the other being independent of both $v_{a c}$ and field strength. An interpretation in terms of a resonant shear vibration seems tempting, but a rigorous light-scattering theory for this case still remains to be derived.

In the cylindrical resonator with quadrupolar electrode geometry inhomogeneous electric fields are generated. A crystalline material subjected to these shows electrophoretic behavior. In addition, resonant torsional vibrations are detected if the suspension is excited by a low-frequency ac field.

\section{Acknowledgements}

We sincerely thank the group of $\mathrm{R}$. Weber for many helpful discussions, and gratefully acknowledge financial support of the DFG.

\section{References}

1. Deggelmanu M, Palberg T, Hagenbüchle M, Maier EE, Krause R, Graf C, Weber R (1991) ] Coll Interface Sci 143:318

2. Palberg T, Härtl W, Wittig U, Versmold $H$, Würth $M$, Simnacher E (1992) J Phys Chem (submitted)

3. Palberg T, Falcoz F, Hecht H, Simnacher E (1992) J Physique (submitted)

4. Dubois-Violette E, Pieranski P, Rothen F, Strzelecki L (1980) J Physique 41:369

5. Alexander S, Chaikin PM, Grant P, Morales G], Pincus P, Hone D (1984) J Chem Phys 80:5776

6. Palberg T, Streicher K, Würth M, König P (1992) Nature (submitted)

7. Palberg T, Versmold H (1989) J Phys Chem 93:5296

8. Bennet AJ, Uzgiris EE (1973) Phys Rev A 8(5):2667

Authors' address:

Dr. T. Palberg

Universität Konstanz

Fakultät f. Physik

Postfach 5560

D-7750 Konstanz, FRG 